\title{
Molecular Weight Dependence on the Morphological Properties of Polyethylene Gels
}

\author{
Chie SAWATARI, Tomoko OKUMURA, and Masaru MATSUO* \\ Department of Clothing Science, Faculty of Home Economics, \\ Nara Women's University, Nara 630 Japan
}

(Received March 25, 1986)

\begin{abstract}
Polyethylene gels were prepared by gelation/crystallization from dilute decalin solutions using five kinds of polyethylenes with different molecular weights and degrees of branching. The decalin was allowed to evaporate from the gels under ambient condition in order to prepare dry gels. The dry gel of ultra-high molecular weight polyethylene (UHMWP) of $\bar{M}_{w}=6 \times 10^{6}$ forms a film but the other low molecular weight polyethylenes (LMWP) with molecular weight lower than $3 \times 10^{5}$ do not form a film. In order to investigate such a difference, the morphological properties of five kinds of dry gels were investigated by scanning electron microscopy, polarized microscopy, small angle light scattering, and small angle X-ray scattering. Within LMWP dry gels, observation reveals spherulitic textures whose crystal lamellae are rotated around a radial direction. In contrast, within the dry gels of UHMWP, there exists rodlike textures as assemblies of large lamellar crystals which are highly oriented with their flat faces parallel to the film surface. To assure ultradrawing up to consistently high draw ratio, a suitable number of entanglements should be formed by tie molecules which connect the crystal lamellae.

KEY WORDS Gelation / Crystallization / Dilute Solution / High

Molecular Weight Polyethylene / Low Molecular Weight Polyethylene /

Entanglements /
\end{abstract}

There have been several methods to produce polyethylene fibers whose Young's modulus and tensile strength are close to the theoretical values. ${ }^{1-15}$ Among these methods, the surface growth method and the gel deformation method can be enumerated as representative examples. As a community of interest, linear polyethylene with ultra-high molecular weight (UHMWP) higher than $1 \times 10^{6}$, was used as specimens for both methods.

The surface method has been developed by Pennings et al. ${ }^{9}$ and Keller et al. ${ }^{10}$ and the maximum values of the Young's modulus and tensile strength of specimens produced, were 142 and $4.7 \mathrm{GPa}$, respectively. Unfortunately, this method has the disadvantage that the production rate of the longitudial crystals is far below the commercially interesting speed. The gel deformation method has been developed by Smith et al. ${ }^{11-13}$ They demonstrated that the effective drawability of high molecular weight by a gel deformation method is dramatically enhanced using specimens spun or cast from semi-dilute solutions to form macroscopic gels. It turns out that for a sufficiently high molecular weight the maximum achievable draw ratio depends principally on the concentration of the solution from which the gel is made. This phenomenon is attributed to a reduced number of entanglements per molecules in solution cast/spun polymers in comparison with those obtained from the melt.

In terms of morphological aspect, we have investigated the drawability of ultra-high

\footnotetext{
* To whom all correspondence should be addressed.
} 
molecular weight polyethylene $\left(\bar{M}_{w}=6 \times 10^{6}\right)$ films produced by gelation/crystallization from dilute solutions, ${ }^{14,15}$ according to the method of Smith and Lemstra. ${ }^{11-13}$ The dried gel films were composed of lamellar crystals oriented parallel to the film surface in a manner similar to mats of single crystals. The facile drawability was found to be due to the extremely high molecular weight and low concentration of the solution which is appropriate to ensure the existence of a suitable level of the entanglements. When dry gel films prepared from such a condition could be consistently elongated at $135^{\circ} \mathrm{C}$ to a remarkably high draw ratio of $\lambda=300$, the Young's modulus and tensile strength were 202 and $6.2 \mathrm{GPa}$, respectively and among the highest reported for polyethylene. However, there has been no report that fibers with high modulus and high strength can be prepared from low molecular weight polyethylenes which have been manufactured commercially. The question arises whether it is essentially impossible to produce such fibers from low molecular weight polyethylene (LMWP).

Drawing of single crystal mats was carried out for LMWP and yielded some interesting results. ${ }^{16,17}$ Statton $^{16}$ studied the drawing behavior of single crystal mats annealed at $110^{\circ} \mathrm{C}$ to examine the effects of annealing on the coherence of a lamellar crystals. Ishikawa et al. ${ }^{17}$ succeeded in drawing singlecrystal mats up to draw ratio over 30 times at temperatures higher than $90^{\circ} \mathrm{C}$. Unfortunately, the mechanical properties of such drawn mats were poor. Recently, Miyasaka et al. ${ }^{18}$ and Kanamoto et al. ${ }^{19}$ have drawn single crystal mats of UHMWP up to high draw ratios for the purpose of obtaining high strength and high modulus fibers (and films), as in our previous works. ${ }^{14,15}$ These results point to an essential problem in relief as to why UHMWP is a required condition to prepare high strength and high modulus fibers through elongation up to consistently high draw ratios.
In this paper, this problem has been approached in terms of morphological aspects in order to study the origin concerning the high drawability and high mechanical properties of dry UHMWP gel films. Accordingly, the morphological properties of dry gels prepared from various molecular weights are investigated by using scanning electron microscopy (SEM), polarizing microscopy (POM), small-angle X-ray scattering (SAXS), wideangle X-ray diffraction (WAXD), and smallangle light scattering (SALS).

\section{EXPERIMENTAL}

Five kinds of linear and branched polyethylenes with different molecular weights were used as specimens. Their molecular weights measured in decalin by several methods are listed in Table I. For viscosity measurements, the dissolution was carried out at $135^{\circ} \mathrm{C}$ under nitrogen and the solutions were stabilized with $0.1 \% \mathrm{w} / \mathrm{w}$ of antioxidant (di-t-butyl-p-cresol). The viscosities of the solutions were determined by an Ubbelohde type capillary viscometer at a temperature of $135^{\circ} \mathrm{C}$ under nitrogen. Gels were prepared by crystallization from solution. Decalin solutions containing approximate amounts of polyethylene and $0.1 \% \mathrm{w} / \mathrm{w}$ of antioxidant were prepared by heating the well-blended polymer/solvent mixture at $135^{\circ} \mathrm{C}$ for $40 \mathrm{~min}$ under nitrogen. The homogenized solution was poured into an aluminum tray that was surrounded by ice water to form a gel. The decalin was allowed to evapolate from the gels under ambient conditions for 30 days. The nearly dried gel was immersed in an excess of ethanol for 30 days to remove the antioxidant and subsequently vacuum-dried for 1 day to remove residual traces of the decalin-ethanol mixture.

Density of the dry gels was measured by a pycnometer with chlorobenzene-toluene as a medium. Since the density is remarkably affected by the residual antioxidant, great care 
The Morphological Properties of Polyethylene Gels

Table I. Characterization of five kinds of polyethylenes, $\bar{M}_{w}=$ the weight-average molecular weight $\bar{M}_{v}=$ the viscosity-average molecular weight

\begin{tabular}{llccc}
\hline & Sample & $\bar{M}_{w}$ & $\bar{M}_{v}$ & Degree of branching \\
\hline a) & Sumikathene G 201 & 170,000 & 41,300 & $2.5 \mathrm{CH}_{3} / 100 \mathrm{C}$ \\
b) & Sholex 6009 & - & 80,100 & $0.7 \mathrm{CH}_{3} / 100 \mathrm{C}$ \\
c) & Sholex super 4551 H & 291,000 & 284,000 & - \\
d) & Sholex super 5551 H & 349,000 & 312,000 & - \\
e) & Hercules 1900/90189 & - & $6,000,000$ & - \\
\hline
\end{tabular}

was taken to remove the antioxidant. The dry gel was cut (or ground) into fragments (or powder) and they were immersed in an excess of ethanol for 30 days prior to measuring the density and subsequently vacuum-dried for 1 day.

The thermal behavior was estimated in terms of melting endotherms of differential scanning calorimetry (DSC) curves. Dry gels, weighing $5 \mathrm{mg}$, were placed in a standard aluminium sample pan. Samples were heated at a constant rate of $10 \mathrm{~K} \mathrm{~min}^{-1}$.

Scanning electron micrographs and polarized micrographs were obtained with a JSM-T 300 in JEOL Co., Ltd. and a Nikon Optiphot Pol (XTP-11) in Nikon Co., Ltd., respectively.

SAXS intensity distribution in the meridional direction was detected with a position sensitive proportional counter (PSPC) and $12 \mathrm{~kW}$ rotating anode $\mathrm{X}$-ray generator (Rigaku RDA-rA operated at $200 \mathrm{~mA}$ and $40 \mathrm{kV}$ ). The measurement was carried out by point focus with a three-slit system. The X-ray source was monochromatized to $\mathrm{Cu}-K_{\alpha}$ radiation with a plate-like graphite monochrometer. The corrected intensity was obtained by substracting the contribution of the background (corresponding to air scattering) from total intensity. The X-ray exposure time was $4 \times 10^{5} \mathrm{~s}$ for each total intensity and air scattering.

Light scattering patterns were obtained with a 3-mW He-Ne gas laser as a light source. diffuse surfaces were avoided by sandwitching the specimens between microcover glasses with silicone oil of an approximate refractive index as an immersion fluid.

\section{RESULTS AND DISCUSSION}

It has been founded that for a sufficiently high molecular weight, the maximum achievable draw ratio depends principally on the concentration of the solution from which the gel is made. This phenomenon is attributed to a reduced number of entanglements per molecule in solution cast/spun polymers in comparison with those obtained from the melt. Qualitative theoretical consideration led to the expectation that an optimum level of entanglements can be realized by a proper choice of solution concentration. The question therefore arises as to how this concentration can be measured. In the previous work, ${ }^{20}$ this question was approached by measurements of solution viscosity since it is basically related to the size or extension in space of macromolecules. The viscosity-concentration data for UHMWP indicated that there exists a critical concentration range where there is an abrupt change in the concentration dependence of viscosity. This critical concentration was interpreted as corresponding to the formation of a coherent network.

Based on the above concept, an apparent critical concentration was obtained for LMWP (Sumikathene G201, Sholex 6009, Sholex super $4551 \mathrm{H}$, and Sholex super $5551 \mathrm{H}$ ). Figure 1 shows the results. The specific viscosity $\eta_{\mathrm{sp}}$ is defined by $\eta_{\mathrm{sp}}=\eta / \eta_{0}-1$, in which $\eta$ and $\eta_{0}$ are the viscosities of solution and solvent, respectively. The viscosity-average molecular weight $\bar{M}_{v}$ in Table I was calculated from the relationship of $[\eta]=K \bar{M}_{v}^{a}$ assuming $K=$ 


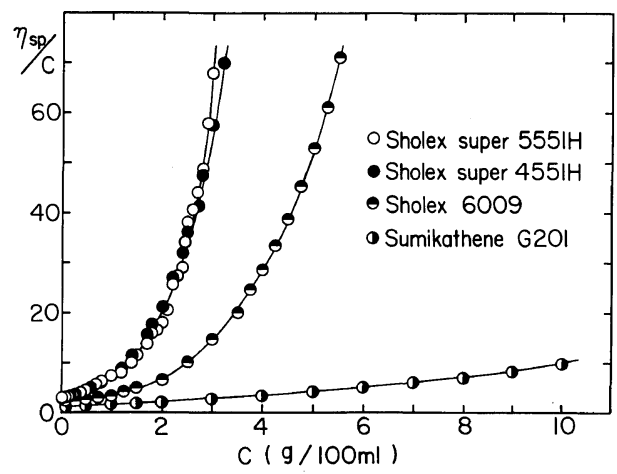

Figure 1. Relationship between reduced viscosity $\eta_{\mathrm{sp}} / c$ and concentration $c$ for the solution of LMWP.

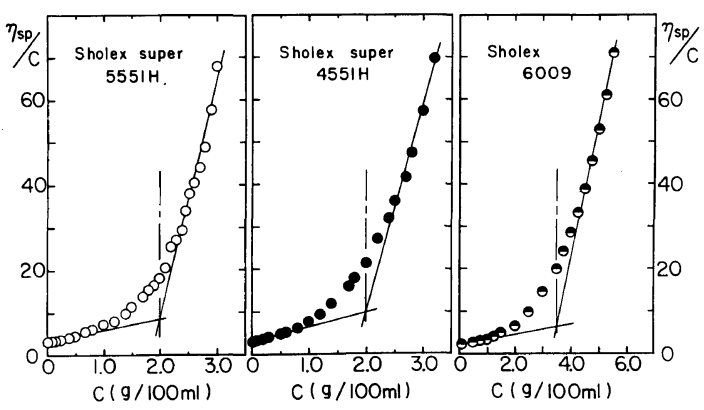

Figure 2. Critical concentrations for the solution of LMWP by the relationship between reduced viscosity $\eta_{\mathrm{sp}} / c$ and concentration $c$.

$6.77 \times 10^{-4}$ and $a=0.67,{ }^{21}$ in which $[\eta]$ is defined by $\lim \eta_{\mathrm{sp}} / c$ ( $c$, concentration). In the concentration range below $10 \mathrm{~g} / 100 \mathrm{ml}, \eta_{\text {sp }} / c$ of the specimen G201 shows a gradual linear increase while these of other specimens $6009,4551 \mathrm{H}$, and $5551 \mathrm{H}$ show a remarkably increasing curve and the degree of the increase becomes considerable with increase in molecular weight of the specimens.

Figure 2 shows a detailed profile of $\eta_{\mathrm{sp}} / c$ against $c$ to discuss the dependence of the critical concentration on molecular weight. Here it should be noted that the plot can be classified approximately into two reduced viscosity regimes, one of low concentration dependence and the other of high concentration dependence. The two straight lines were drawn by a least square method, by which it was relatively simple to fit a tangent to the

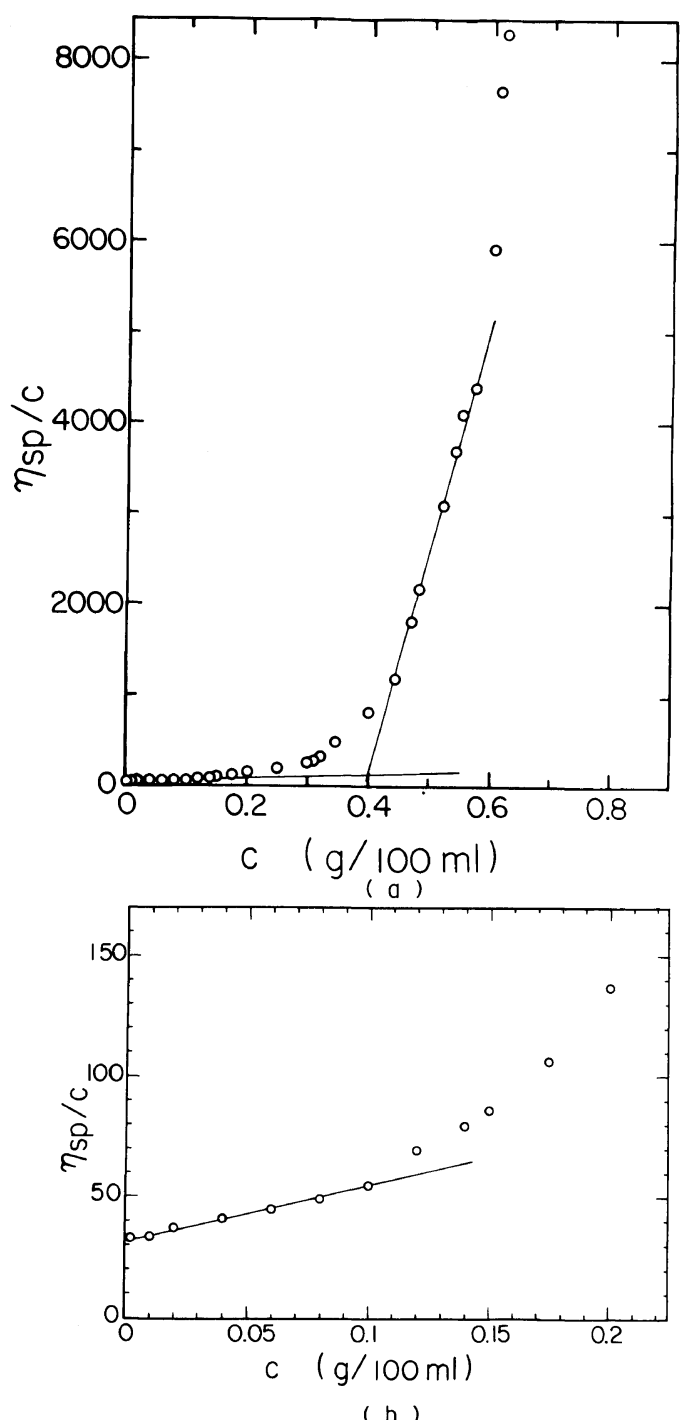

Figure 3. (a) Critical concentration for the solution of UHMWP by the relationship between reduced viscosity $\eta_{\mathrm{sp}} / c$ and concentration $c$. (b) Relationship between reduced viscosity $\eta_{\mathrm{sp}} / c$ and concentration $c$ in the range lower than $0.2 \mathrm{~g} / 100 \mathrm{ml}$.

data. The intersection of the two linear lines shifts to lower concentration with increasing the molecular weight. The intersections of the specimens $6009,4551 \mathrm{H}$, and $5551 \mathrm{H}$ and about $3.5,2.0$, and 2.0, respectively. This tendency becomes considerable for UHMWP (Hercules 1900/90189).

Figure 3 shows the reduced viscosity con- 
centration relationship for UHMWP, in which (a) reveals the profile in the concentration range from 0 to $6.2 \mathrm{~g} / 100 \mathrm{ml}$ and (b) the detailed profile of the concentration lower than $0.2 \mathrm{~g} / 100 \mathrm{ml}$. A similar result has been already reported but the current work provides a more detailed result in Figure 3. As discussed before,$^{20}$ the plot can be classified into two reduced viscosity regimes, one of weak concentration dependence (lower than $0.1 \mathrm{~g}$ / $100 \mathrm{ml}$ ) and the other of strong concentration dependence between 0.44 and $0.573 \mathrm{~g} /$ $100 \mathrm{ml}$, as approximately linear regions. The intersection of the two linear segments was around $0.4 \mathrm{~g} / 100 \mathrm{ml}$. Beyond $0.6 \mathrm{~g} / 100 \mathrm{ml}$, the measurement was very difficult because of the high viscosity and the data were scattered. The viscosity-average molecular weight $\bar{M}_{v}$ in Table I for UHMWP was calculated on the basis of the plot in Figure 3(b).

According to our recent work, ${ }^{20}$ it was found that for UHMWP (Hercules 1900/ 90189) when the dry gel films were produced by gelation/crystallization from a solution with $0.4 \mathrm{~g} / 100 \mathrm{ml}$ corresponding to the intersection shown in Figure 3(a), they could easily be elongated at $135^{\circ} \mathrm{C}$ to a remarkably high draw ratio of $\lambda=300$. Namely, the possibility of successfully drawing up to $\lambda=300$ becomes lower as the concentration is away from $0.4 \mathrm{~g} / 100 \mathrm{ml}$. The possibility becomes zero below $0.2 \mathrm{~g} / 100 \mathrm{ml}$ and beyond $0.6 \mathrm{~g} / 100 \mathrm{ml}$; the maximum draw ratio at $0.2 \mathrm{~g} / 100 \mathrm{ml}$ and $0.6 \mathrm{~g} / 100 \mathrm{ml}$ were almost $\lambda=100$ and 250 , respectively. Accordingly, it may be expected that most of the chain molecules in the regime of low concentration are random coils having coupling entanglements that will be predominantly intra-molecular in nature. On the other hand, solutions corresponding to the regime of high concentration are thought to consist of interpenetrating random coils which form a large number of coupling entanglements that are both intra- and intermolecular.

In order to study the changes in morpho-

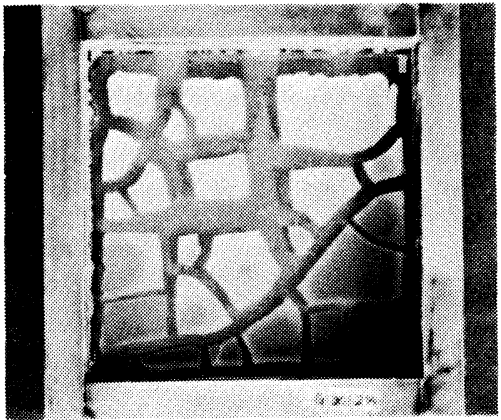

(a) G201

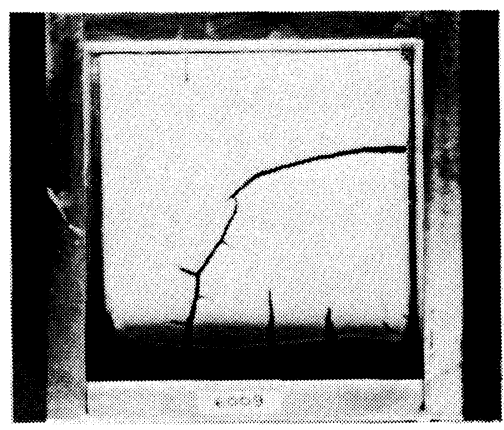

(b) 6009

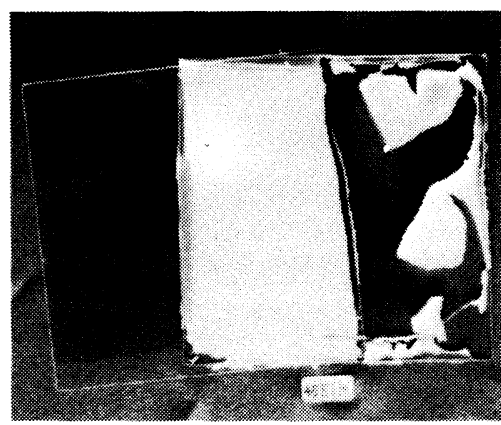

(c) $4551 \mathrm{H}$

Figure 4. Dry gels of LMWP, (a) G 201, (b) 6009, and (c) $4551 \mathrm{H}$.

logical properties of dry gels with increasing molecular weight, four kinds of polyethylenes except G201 were crystallized from the solution with each concentration corresponding to the intersection. The sample G201, the molecular weight being the lowest among five samples, has no intersection and $2.0 \mathrm{~g} /$ $100 \mathrm{ml}$ is employed as a concentration to prepare the gels arbitrary. Figure 4 shows dry 
gels, in which (a), (b), and (c) are G201, 6009, and $4551 \mathrm{H}$, respectively. As can be seen in the figure, these dry gels were composed of powder like single crystals. The gels were cracked on the drying under ambient conditions. When the half-dried gel was sandwitched between glass plates and dried, crackes could be avoided as shown in Figure 4(c) but the resultant dry gels did not form a film and they were brittle like single crystal mats.

In a macroscopic shape, the gels of $5551 \mathrm{H}$ were similar to those of $4551 \mathrm{H}$. The gel of $5551 \mathrm{H}$ was very brittle like single crystal mats. In our subsequent experiment, it was confirmed that LMWP specimens used in this experiment have no ability to form films after evaporation of solvents from the gels prepared by gelation/crystallization using the solution with $5 \mathrm{~g} / 100 \mathrm{ml}$. This concentration was maximum and beyond this point, it was impossible to prepare gels technically in our laboratory. This is due to an extremely rapid crystallization before pouring the solutions into aluminum tray. In contrast, our recent work $^{20}$ showed that dry gel films could be formed on crystallizing from solutions with

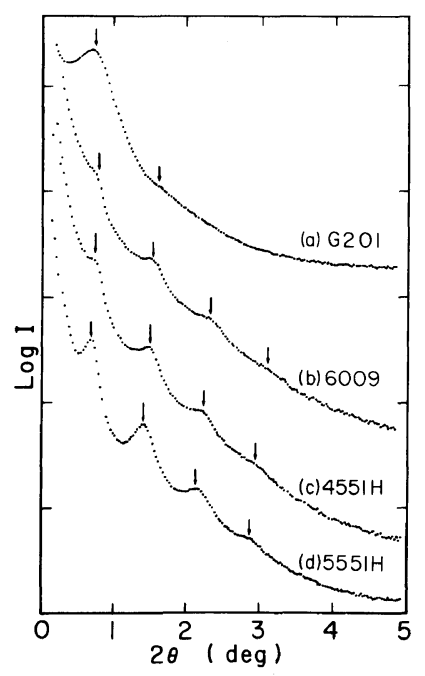

Figure 5. SAXS intensity distribution as a function of twice the Bragg angle $(2 \theta)$ in the meridional direction for dry gels of four kinds of LMWP dry gels. concentrations above $0.1 \mathrm{~g} / 100 \mathrm{ml}$. A series of macroscopic results indicated that formability of dry gel films is dependent upon molecular weight; LMWP whose molecular weight is lower than 400,000 can not form dry gel films. Since molecular weight plays an important role to form dry gel films, it is of interest to consider this reason in terms of morphological aspects.

Figure 5 shows SAXS intensity distribution in the meridional direction from dry gels of four kinds of LMWP when the incident beam was directed parallel to the film surface (end view). It is of interest to note that the scattered maxima become distinct and move slightly close to the center of the scattering angle as molecular weight increases; the scattered intensity from G201 shows up to the second order maxima, while those of $6009,4551 \mathrm{H}$, and $5551 \mathrm{H}$ show up to the fourth order maxima. The result of four SAXS intensity

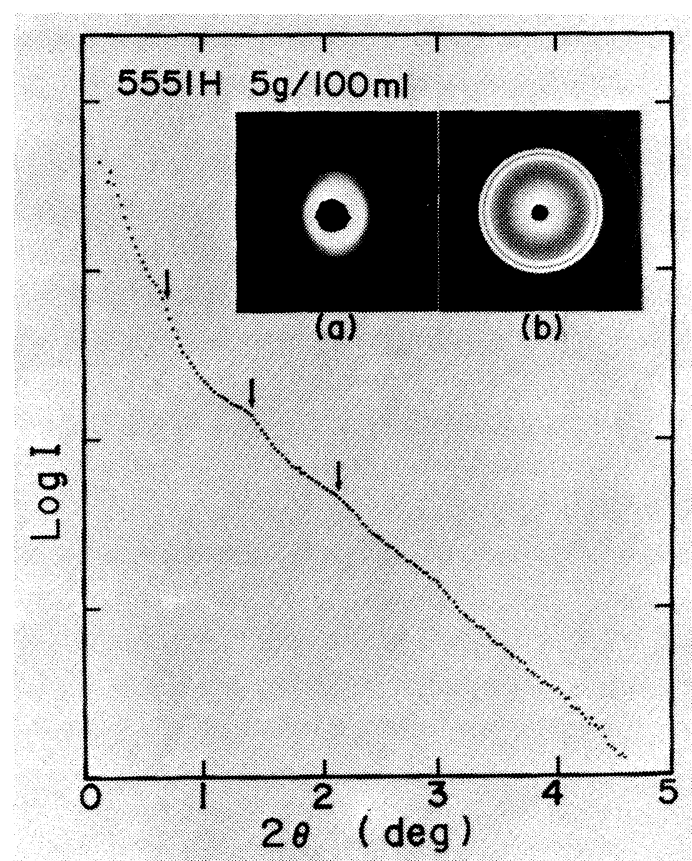

Figure 6. WAXD pattern, SAXS pattern, and SAXS intensity distribution as a function of twice the Bragg angle $(2 \theta)$ in the meridional direction for LMWP $5551 \mathrm{H}$ prepared from the solution with the concentration of $5 \mathrm{~g} / 100 \mathrm{ml}$. 


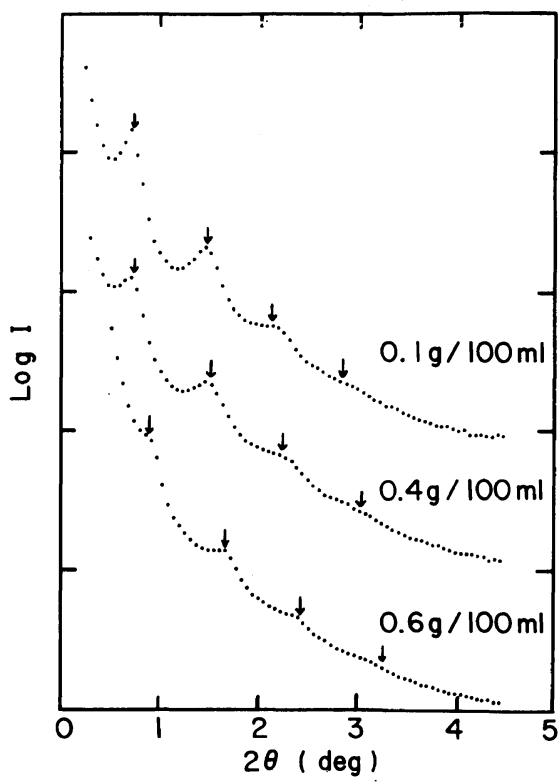

Figure 7. Three SAXS intensity distributions as a function of twice the Bragg angle $(2 \theta)$ in the meridional direction for UHMWP dry gel films crystallized from solutions with concentrations of $0.1,0.4$, and $0.6 \mathrm{~g} / 100 \mathrm{ml}$.

distributions indicates that a dry gel is composed of crystal lamellae and crystal lamellae were oriented predominantly with their large flat faces parallel to the film surfaces in a manner similar to mats of single crystals. It may be expected that such orientational behavior of crystal lamellae arises when the gels are dried by slow evaporation of the solvent and therefore the orientational degree becomes considerable with increasing molecular weight since the area of their large flat faces becomes larger.

Figure 6 shows WAXD and SAXS patterns, and SAXS intensity distribution in the meridional direction for $5551 \mathrm{H}$ crystallized from solutions with a concentration of $5 \mathrm{~g} / 100 \mathrm{ml}$, when the incident beam was directed parallel to the gel surface. The WAXD pattern shows circular diffraction rings and the SAXS patterns circular type diffuse scattering. Furthermore, the intensity distribution shows up to the third order maxima. These results in- dicate that the dry gel is also composed of crystal lamellae like single crystal mats prepared from the solution with the critical concentration but the lamellae were oriented randomly within the gel. This means that there is an increase in the orientational fluctuation of the crystal lamellae (that were oriented with their flat faces parallel to the film surface) in comparison with (the SAXS intensity distribution of) the gels prepared from the critical concentration. (Figure 5(d)).

The solutions corresponding to the region of high concentration are thought to consist of interpenetrating random coils which form a large number of coupling entanglements that are both intra- and inter-molecular. However, even when a gel was prepared from this solution, the resultant dry gel could not form a film as discussed before and became isolated single crystals. Under such a condition, it is evident that the resultant lamellae are not interconnected by chain molecules when each molecule is completely incorporated into lamellar crystals. Judging from this phenomenon, it may be expected that crystallization from solutions containing a large number of coupling entanglements allows formation of folded chain crystals where each molecule is completely incorporated into lamellar crystals. This is quite different from the morphological properties of UHMWP gels which have ability to form films.

Figure 7 shows SAXS intensity distribution in the meridional direction for UHMWP (Hercules 1900/90189) crystallized from solutions with $0.1,0.4$, and $0.6 \mathrm{~g} / 100 \mathrm{ml}$ concentrations. This figure has already been represented elsewhere ${ }^{22}$ but it is shown to discuss the difference of morphological properties between LMWP and UHMWP gels. Among three concentrations, $0.4 \mathrm{~g} / 100 \mathrm{ml}$ corresponds to the intersection of the two linear lines as shown in Figure 3. The concentration causes a significant change for the scattered intensity profile. The scattered intensity for all specimens shows up to the fourth order maxima 


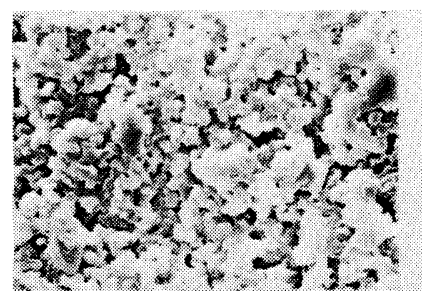

(a) 6201

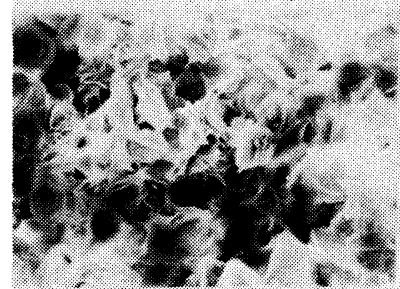

(b) 6009

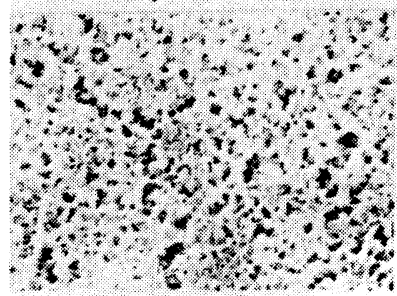

(c) $455 \mathrm{IH}$

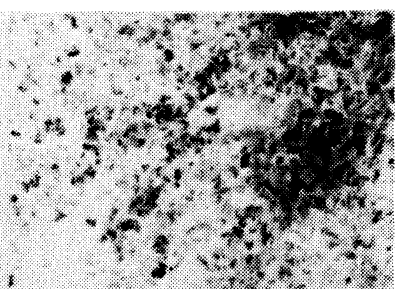

(d) $5551 \mathrm{H}$

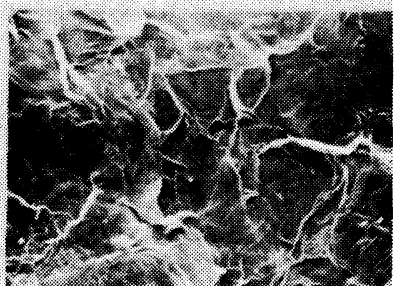

(e)Hercules

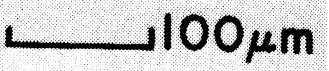

Figure 8. A SEM of dry gels of polyethylene with five kinds of molecular weights.

whose magnitude decreases with increasing concentration of solution. Interestingly, it is evident that the intensity curves for the gel films prepared with solutions with 0.1 and $0.4 \mathrm{~g} / 100 \mathrm{ml}$ are similar to those (c) and (d) in Figure 5. This means that the gels prepared from critical concentration show similar orientational fluctuation disorder and/or thickness fluctuation of crystal lamellae, when polyethylene whose molecular weight is beyond 280,000 is used as the specimen. Accordingly, these fluctuations are essentially insufficient to explain the origin of film formability.

Figure 8 shows the change in the appearance of dry gels with increasing molecular weight under SEM. Observations revealed that dry gels of four kinds of LMWP show the existence of spherulitic texture while dry gels of UHMWP show a fibrillar one like sponge tissue which was observed in our previous works. ${ }^{23,24}$ Such spherulitic and fibrillar textures are also confirmed by polarizing microscopy and $H_{\mathrm{v}}$ light scattering techniques.

Figure 9 shows polarized micrographs of dry gels. In order to observe the textures within dry gels, very thin dry gels were prepared by pouring a drop of gel on a glass plate and drying under ambient conditions. The morphology of four kinds of LMWP shows spherulitic textures which are negative birefringent, showing a black Maltese cross and ring structure clearly. This observation reveals the two dimensional spherulites and this morphology is in contrast with that of UHMWP showing fibrillar textures.

Figure 10 shows the corresponding $H_{\mathrm{v}}$ light scattering patterns. The scattering from four kinds of LMWP shows a four-leaf clover pattern with a maximum in each lobe in the 


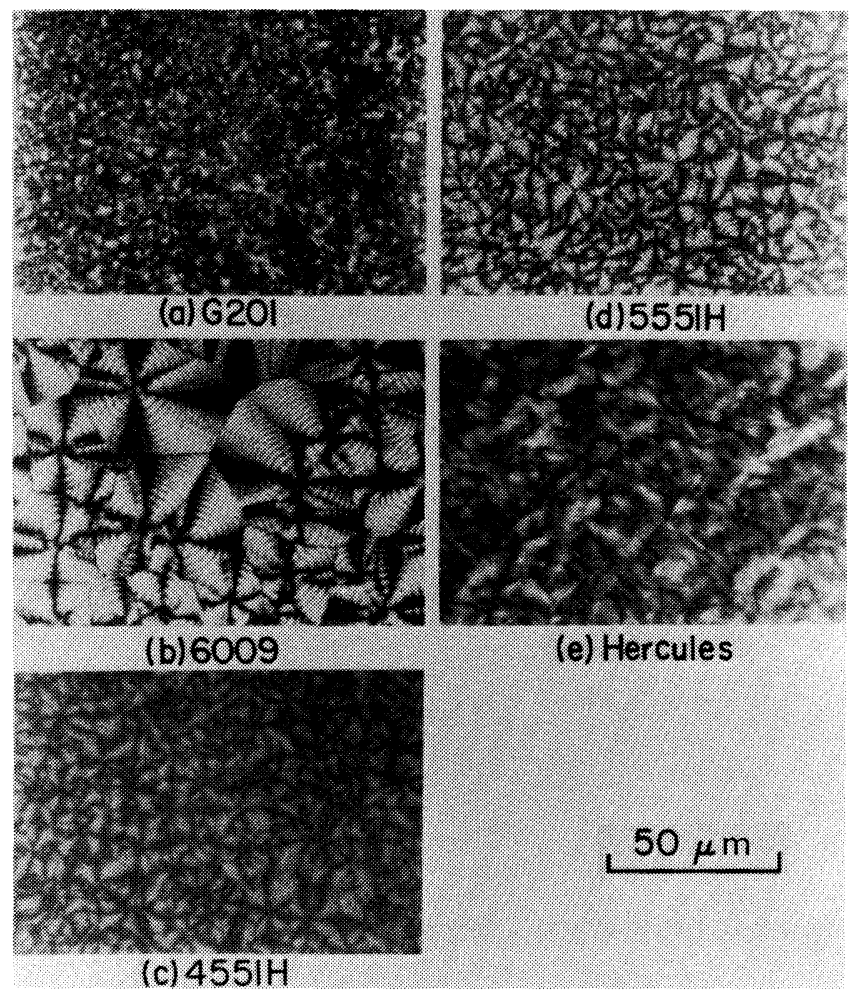

Figure 9. Polarized micrographs of dry gels of polyethylene with five kinds of molecular weights.

polar direction along the azimuthal angle of highest intensity. ${ }^{25}$ This is characteristic of the scattering from undeformed spherulites. The scattering from the UHMWP dry gel film displays lobes of a diffuse X-type. The intensity had a maximum in the center and it decreased monotonically with increasing scattering angle. This observation is indicative of scattering from rodlike textures.

Based on a series of experimental results in Figures $8-10$, it turns out that the dry gels for LMWP are constructed from spherulitic textures and crystal lamellae, the crystal $c$ axes being oriented perpendicular to the large flat faces, are rotated around the radial direction within the spherulite, while the dry gel films for UHMWP are constructed from fibrillar (rodlike) textures oriented predominantly parallel to the dry gel film surface and the optical axes, corresponding to the crystal $c$-axes in this system, are oriented normal to the film surface but show orientational disorder with respect to the rod axis. ${ }^{27}$

In order to study in more detailed morphological properties of dry gels and melt films, the change in $H_{\mathrm{v}}$ light scattering pattern from dry gels is discussed in relation to the concentration of solutions to crystallize and in comparison with that of melt films. Figures $11-13$ are the results. Figure 11 shows the $H_{\mathrm{v}}$ scattering patterns from the specimen 6009 . The melt films were prepared after melting the dry gels under nitrogen at $160^{\circ} \mathrm{C}$ and cooling down slowly to room temperature. As can be seen in Figure 11, the scattering lobes becomes larger with increasing concentration. This implies that the size of the spherulites becomes smaller as the concentration increases. A similar tendency was observed for the specimen G 201. 


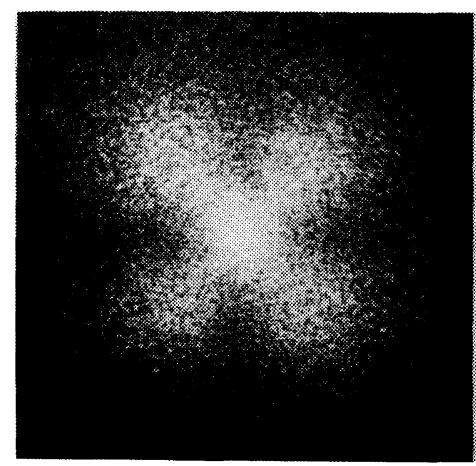

(a) G201

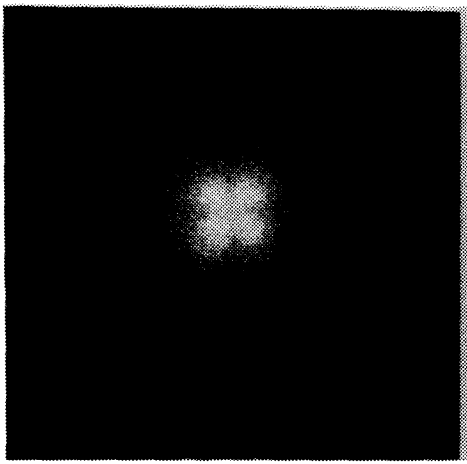

(b) 6009

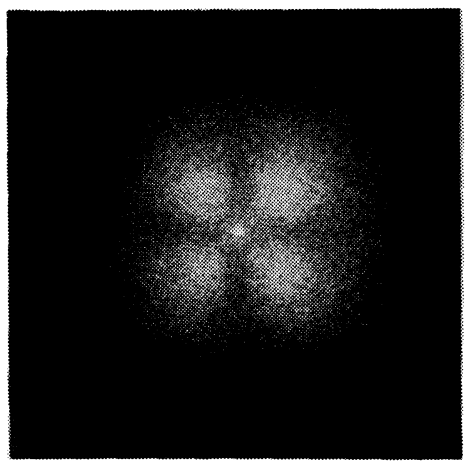

(c) $4551 \mathrm{H}$

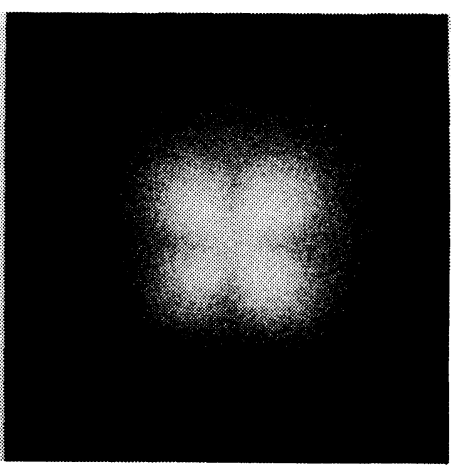

(d) $5551 \mathrm{H}$

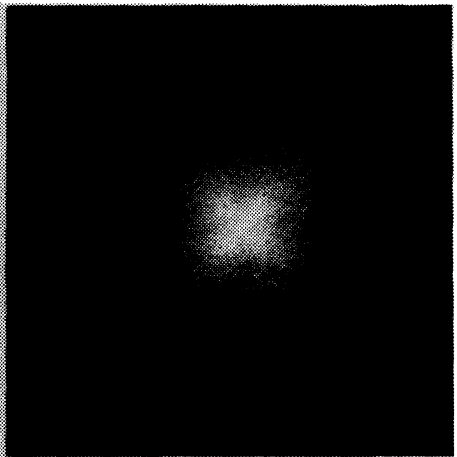

(e) Hercules

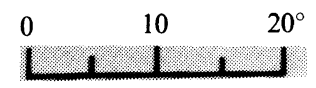

Figure 10. $H_{\mathrm{v}}$ light scattering patterns observed for dry gels of polyethylene with five kinds of molecular weights.

Figure 12 shows the $H_{\mathrm{v}}$ scattering patterns from the specimen $4551 \mathrm{H}$. The patterns characterizing the scattering from perfect spherulites within the dry gel is hardly affected by the concentration of solution in the range from 1 to $3 \mathrm{~g} / 100 \mathrm{ml}$ on crystallization. In contrast, the scattered intensity from the melt film is not zero at the center of scattering and the pattern is a modification removed from the four leaf clover pattern so as to have a rather long leafstalk. Such a pattern has been observed for melt-crystallized polyethylene films ${ }^{28}$ and 
The Morphological Properties of Polyethylene Gels

Sholex 6009

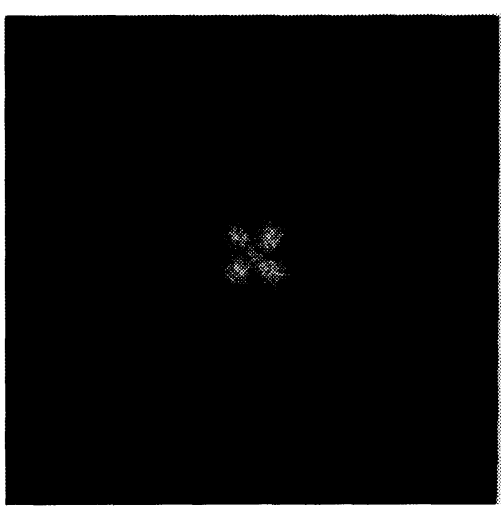

(a) $1 \mathrm{~g} / 100 \mathrm{ml}$

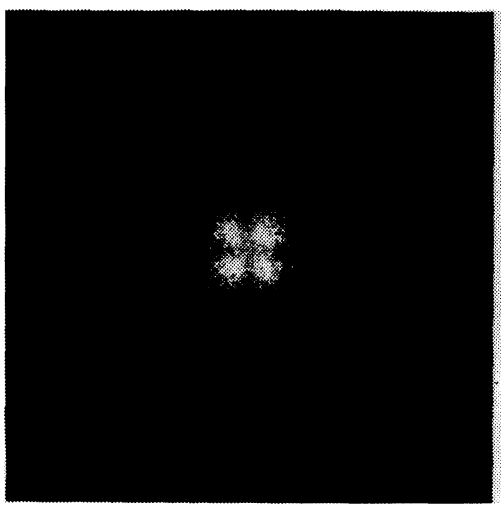

(b) $3.5 \mathrm{~g} / 100 \mathrm{ml}$

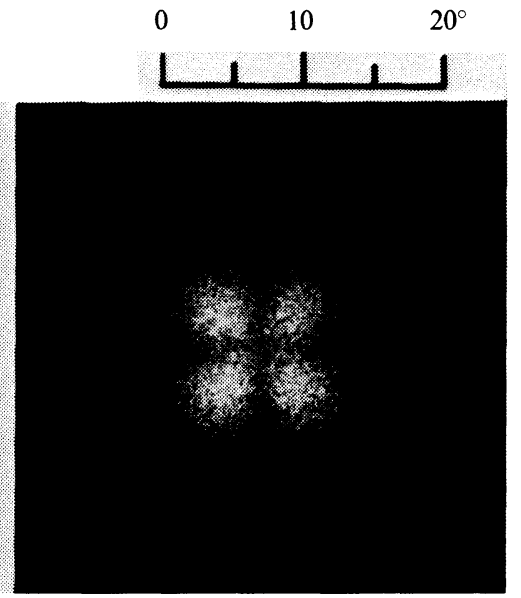

(c) $5 \mathrm{~g} / 100 \mathrm{ml}$

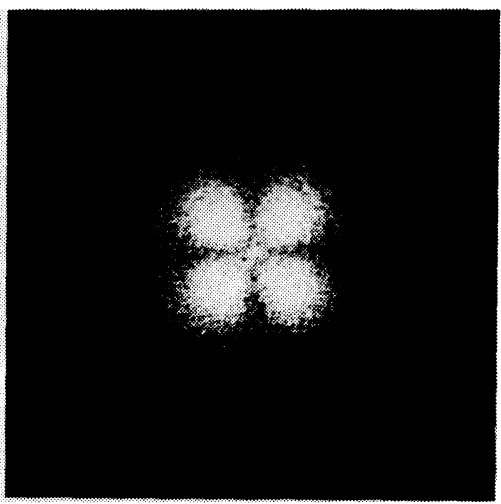

(d) melt

Figure 11. $H_{\mathrm{v}}$ light scattering patterns observed for dry gels of LMWP (6009) crystallized from solutions with concentrations of $1,3.5$, and $5 \mathrm{~g} / 100 \mathrm{ml}$ and the melt film.

analysis was done by taking the distribution of the size in spherulites into account, taking the spherulite anisotropy, as a function of distance from the center of the spherulite, and further making the boundary of the spherulite less clear.

Table II shows the radius of a spherulite of the dried gel as a function of the concentration of solution to prepare a gel and radius of spherulites within the melt films. Equations to estimate the radius were derived by Stein et al. for the two-dimensional ${ }^{28}$ and three dimensional $^{25}$ spherulites. In actual calcula-
Table II. Radius of spherulites within dry gels prepared from solutions with various concentration as well as within a melt film. Measurement was carried out for five kinds of polyethylenes with different molecular weights

\begin{tabular}{ccccc}
\hline $\begin{array}{c}\text { Concentration } \\
(\mathrm{g} / 100 \mathrm{ml})\end{array}$ & (a) G201 & (b) 6009 & (c) $4551 \mathrm{H}$ (d) $5551 \mathrm{H}$ \\
\hline 1 & 3.63 & 13.08 & 5.24 & 4.99 \\
2 & 3.63 & & 5.24 & 5.82 \\
3 & & & 4.76 & 4.37 \\
3.5 & & 13.08 & & \\
4 & 3.52 & & & \\
5 & & 7.67 & & \\
A melt film & 2.60 & 6.54 & 3.18 & 3.00 \\
\hline
\end{tabular}




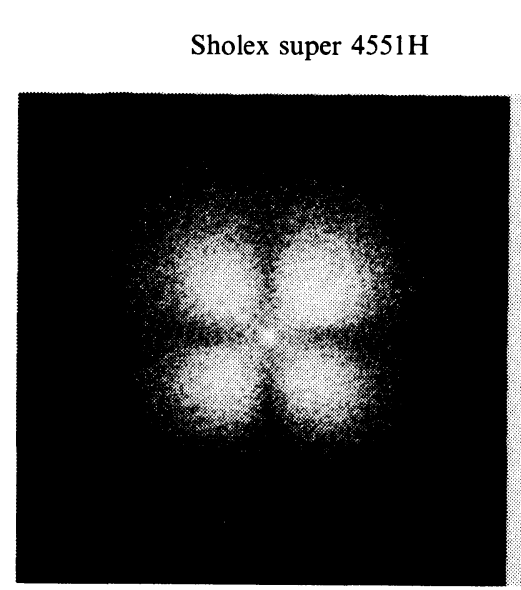

(a) $1 \mathrm{~g} / 100 \mathrm{ml}$

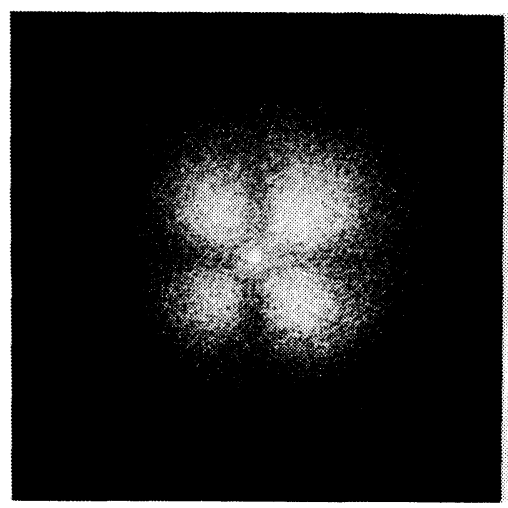

(b) $2 \mathrm{~g} / 100 \mathrm{ml}$

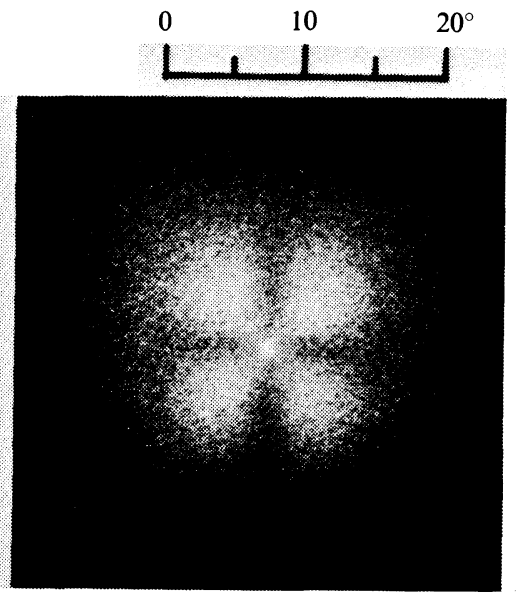

(c) $3 \mathrm{~g} / 100 \mathrm{ml}$

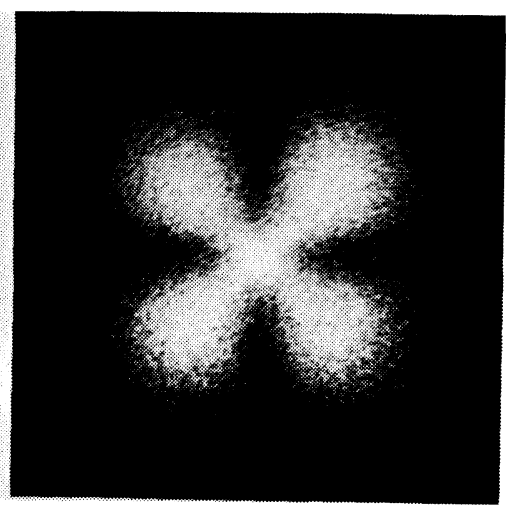

(d) melt

Figure 12. $H_{\mathrm{v}}$ light scattering patterns observed for dry gels of LMWP $(4551 \mathrm{H})$ crystallized from solutions with concentrations of 1,2 , and $3 \mathrm{~g} / 100 \mathrm{ml}$ and the melt film.

tion by Stein's equations, it is assumed that the spherulites within a dry gel and those within a melt film are two-dimensional and three-dimensional ones, respectively. The radius of spherulites tends to increase as the concentration of the solution decreases. The spherulitic radius within the dry gel is larger than that within the melt films.

Figure 13 shows the scattering patterns from UHMWP gel films and melt film. All the patterns exhibit X-type ones. This indicates that the superstructures within the UHMWP gel film become rodlike textures. However, we could find the existence of spherulites within a UHMWP melt film, although the possibility of the existence is less than that of the existence of rods. The co-existence of rods and spherulites is probably due to the fact that UHMWP used in this experiment has wide molecular weight distribution. Namely, it may be expected that when UHMWP is melt and cooled down slowly to room temperature, long chains crystallize with each other to form rods and subsequently short chains crystallize to form spherulites.

A series of experimental results in Figures $8-13$ indicates that the morphology of polyethylene is sensitive to the molecular weight 
Hercules 1900

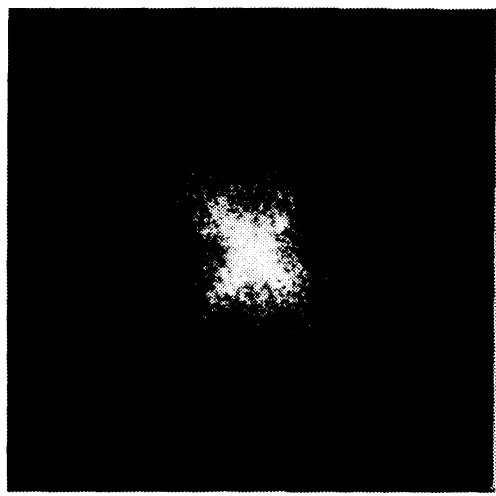

(a) $0.1 \mathrm{~g} / 100 \mathrm{ml}$

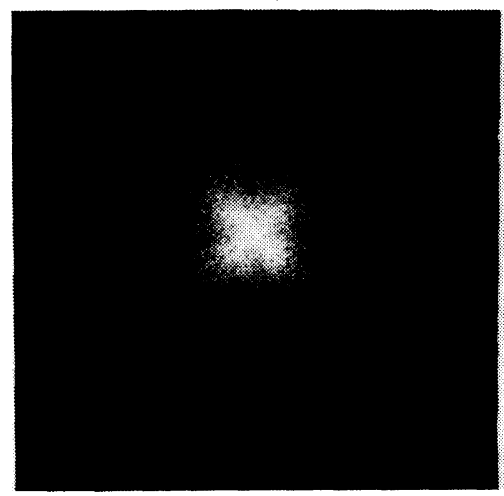

(b) $0.4 \mathrm{~g} / 100 \mathrm{ml}$

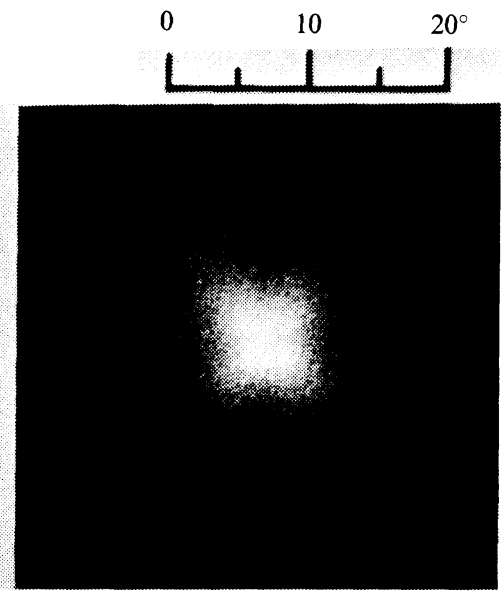

(c) $0.6 \mathrm{~g} / 100 \mathrm{ml}$

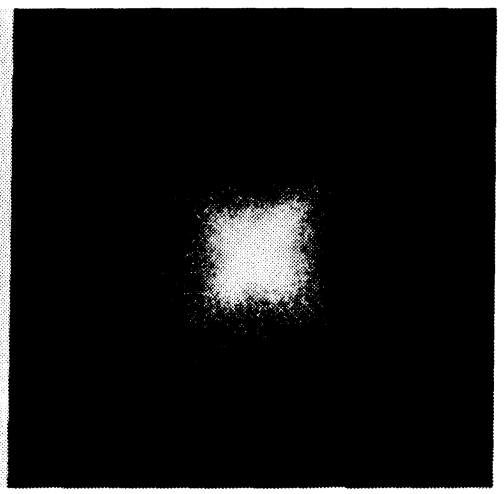

(d) melt

Figure 13. $H_{\mathrm{v}}$ light scattering patterns observed for dry gel films of UHMWP (Hercules 1900) crystallized from solutions with concentrations of $0.1,0.4$, and $0.6 \mathrm{~g} / 100 \mathrm{ml}$ and the melt film.

and this concept provides a basis for such a ambiguous assumption as discussed in the previous work. ${ }^{23}$ The previous work reported that the existence of fibrillar texture prepared without stress is very interesting because it is well known that polyethylene crystallized from stressed polymer melts and solutions has fibrillar (rodlike) textures whereas that crystallized without stress has spherulitic texture and this is presumably due to many constitutional factors such as molecular weight, quenching temperature and solution concentration. However, our current result pointed out that the super- structures of polyethylene crystallized without stress is only dependent upon molecular weight but is independent of quenching temperature and solution concentration. This result supports the experimental result of Mandelkern et al. ${ }^{29}$ the morphology of polyethylene is sensitive to molecular weight distribution.

The question arises as to why it is impossible to prepare dried gel films using LMWP. In order to answer the question, the crystallinities of LMWP as well as UHMWP were measured for dried gels which were crystallized from solutions with various concentrations 
and are listed in Table III. The values of specimens except G201 are almost in the range from 80 to $86 \%$ and are hardly affected by molecular weight, as long as polyethylene gels were prepared by the solution with the given concentrations. The crystallinity of $5551 \mathrm{H}$ crystallized from $5 \%$ solution is $80 \%$. The values of G 201 lower than those of other LMWP are probably due to the high degree of branching which hampers crystallization as listed in Table I. The crystallinities of all the resultant gels except $G 201$ are independent of molecular weight. This result is very important in considering the origin of ultradrawing of dry gels. It should be noted that the length of total segments to form amorphous phase within one polymer chain in

Table III. Concentration dependence on crystallinity of dry gels of five kinds of polyethylenes. Unit ( $\%)$

\begin{tabular}{cccccc}
\hline $\begin{array}{c}\text { Concentration } \\
(\mathrm{g} / 100 \mathrm{ml})\end{array}$ & $\begin{array}{c}\text { (a) } \\
\mathrm{G} 201\end{array}$ & $\begin{array}{c}\text { (b) } \\
\text { 6009 }\end{array}$ & $\begin{array}{c}\text { (c) } \\
\text { (c551H }\end{array}$ & $\begin{array}{c}(\mathrm{d}) \\
5551 \mathrm{H}\end{array}$ & $\begin{array}{c}(\mathrm{e}) \\
\text { Her. 1900 }\end{array}$ \\
\hline 0.1 & & & & & 86.2 \\
0.4 & & & & & 84.0 \\
0.6 & & & & & 84.2 \\
1 & 54.4 & 81.8 & 80.8 & 82.7 & \\
2 & 52.4 & & 80.4 & 82.2 & \\
3 & & & 80.4 & 82.1 & \\
3.5 & & 81.1 & & & \\
4 & 53.6 & & & & \\
5 & & 81.1 & & & \\
\hline
\end{tabular}

Table IV. Annealing temperature dependence on crystallinity of dry gel polyethylene with different kinds of molecular weights.

The annealing time was $30 \mathrm{~min}$, Unit $(\%)$

\begin{tabular}{cccccc}
\hline $\begin{array}{c}\text { Annealing } \\
\text { temp } /{ }^{\circ} \mathrm{C}\end{array}$ & $\begin{array}{c}(\mathrm{a}) \\
\text { G201 }\end{array}$ & $\begin{array}{c}\text { (b) } \\
6009\end{array}$ & $\begin{array}{c}\text { (c) } \\
4551 \mathrm{H}\end{array}$ & $\begin{array}{c}\text { (d) } \\
\text { (d) }\end{array}$ & $\begin{array}{c}\text { (e) } \\
\text { Her. 1900 }\end{array}$ \\
\hline $\begin{array}{c}\text { Untreated } \\
50\end{array}$ & 52.4 & 81.1 & 80.4 & 82.4 & 84.0 \\
70 & 52.5 & 81.4 & 80.6 & 82.3 & 84.1 \\
90 & 52.5 & 81.8 & 80.8 & 82.3 & 84.2 \\
110 & 51.6 & 82.0 & 80.8 & 82.5 & 84.4 \\
130 & 47.6 & 82.6 & 80.8 & 82.0 & 85.5 \\
140 & 44.0 & 82.7 & 75.4 & 80.1 & 87.3 \\
150 & 42.3 & 80.8 & 68.2 & 76.7 & 87.4 \\
& 42.0 & 69.5 & 62.5 & 60.9 & 81.7 \\
\hline
\end{tabular}

the case of UHMWP is much longer than that in the case of LMWP. Namely, the total segments per molecule to form amorphous phase for UHMWP are almost twenty times longer than that of $5551 \mathrm{H}$ which is the highest molecular weight among four kinds of LMWP. If this is the case, it may be expected that UHMWP ensures the existence of a suitable level of the entanglements that act as intermolecular crosslinks and effectively transmit the drawing force, while LMWP has no ability to form a gel film because of very few entanglements.

Table IV reveals the change in crystallinity with increasing annealing temperature. In this experiment, the annealing process of dry gels was carried out for $30 \mathrm{~min}$ under nitrogen and cooled down slowly to room temperature. Beyond the melting point, all dry gels formed films with cooling. In so doing, the crystallinities for all specimens decreased considerably. This should be accompanied by melting and there should be a corresponding increase in entanglements. The increase in entanglements promotes formability of films. It should be noted that a considerable increase in entanglements hampers the drawability of films. Namely, as reported by Capaccio et $a l .{ }^{30}$ and Warner, ${ }^{31}$ melt films of UHMWP could not be drawn to ratios higher than 5-10.

Figure 14 presents the change in the profile of the DSC curves with increasing molecular weight. Generally, with increasing molecular weight, the position of peak associated with heat of fusion shifts to higher temperatures except for specimens (b) 6009 and (c) 4551 H. This tendency suggests that the heatresistant property becomes significant to the increase in molecular weight.

Returning to Figures 5 and 7, the SAXS profiles were interpreted already as indicating that dry gels are composed of a stack of lamellar crystals that are highly oriented with their large flat faces parallel to the film surface. The SAXS profiles from these dry gels 


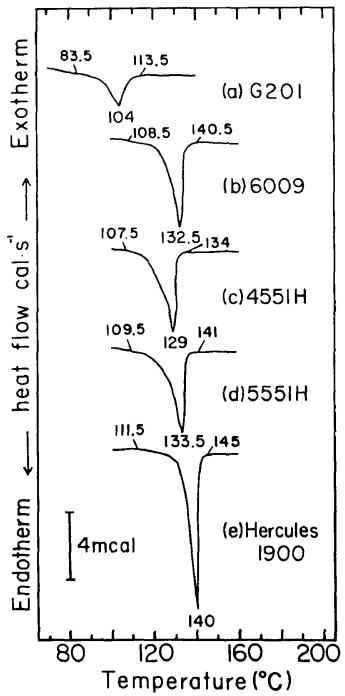

Figure 14. DSC curves of dry gels of polyethylene with five kinds of molecular weights.

are thus similar to those obtained from a sedimented mat of single crystals. This indicates that the dry gels composed of large lamellar crystals stacked on top of one another to form a periodic structure perpendicular to the plane of dry gel. This system is not so difficult in formulating an equation of scattered intensity distribution. In the previous works, on SAXS intensity distribution, the theoretical calculation was carried out for two cases; one is that the scattering is caused by the excess electron density ${ }^{32}$ and the other is that the scattering is caused by positive and negative deviation from the average density of the sample. ${ }^{33,34}$ Considering a somewhat complicated but realistic system, the equation of scattered intensity contains a number of parameters and it was very difficult to estimate an exact value for all parameters by computer. In order to avoid such trouble, the orientational fluctuation of crystal lamellae and fluctuation of lamellar size were neglected and the analysis was limited for two phase structures composed of completely oriented lamellar microdomains. Based on this assumption, attension was focused on a quantitative estimation of the boundary (transition) regions $t$ corresponding to folded loops on the basis of SAXS intensity distribution at larger scattering angles than those in Figures 5 and 7. On substracting the background scattering arising from the amorphous order and thermal density fluctuation from the total scattered intensity, the background scattering was assumed to be given by a straight line. ${ }^{35}$ Through trial and error, however, it was found that the manner of substracting the background scattering did not much affect the final value of the density transition at the interface.

The system to be considered here is the one which has one-dimensional electron density fluctuation along a direction normal to the lamellar interfaces and the density variation is periodic. The variation deviates from the variation of an ideal two-phase system in which the density variation occurs discontinuously from electron density of crystal lamellae and void.

If the electron density variation is given by a Gaussian function, the scattered intensity at large angle tail $I(s)$, corrected for background scattering, is given by ${ }^{35}$

$$
I(s)=(\text { const }) s^{-2} \exp \left(-4 \pi^{2} \sigma^{2} s^{2}\right)
$$

where

$$
s=2 \sin \theta / \lambda^{\prime}
$$

where $\lambda^{\prime}$ is the wavelength of the $\mathrm{X}$-ray and $2 \theta$ is the scattering angle. $\sigma$ is the parameter denoting standard deviation, characterizing the diffuseness of the boundary and it is given the interfacial thickness $t$, as follows:

$$
\sigma=(2 \pi)^{1 / 2} t
$$

The value of $t$ can be evaluated from the slope and the intercept at $s^{-2}=0$ in the plot of $I(s)$ vs. $s^{-2.36}$

Figure 15 shows the results for two kinds of dry gels $4551 \mathrm{H}$ and $5551 \mathrm{H}$ corresponding to Figure 5, while Figure 16 shows the results for UHMWP corresponding to Figure 7.

Table V summarizes the periodic distance $L$ 


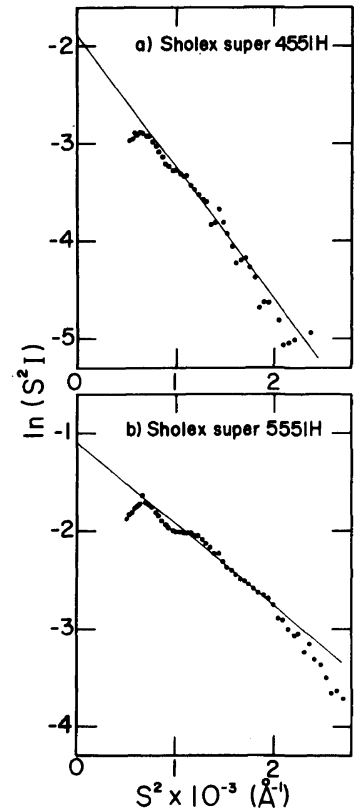

Figure 15. Full analysis of the interfacial thickness, $\ln \left(s^{2} I(s)\right) v s . s^{2}$ of dry gels of LMWP (a) $4551 \mathrm{H}$ and (b) $5551 \mathrm{H}$.

Table V. Periodic distance and interfacial thickness of polyethylene gels with four kinds of molecular weights which were prepared by gelation/ crystallization from solution

\begin{tabular}{ccc}
\hline Specimen & $\begin{array}{c}\text { Periodic } \\
\text { distance, } \\
L / \AA\end{array}$ & $\begin{array}{c}\text { Interfacial } \\
\text { thickness, } \\
t / \AA\end{array}$ \\
\hline $\begin{array}{c}\text { UHMWP } \\
(0.1 \mathrm{~g} / 100 \mathrm{ml}) \\
\text { UHMWP }\end{array}$ & 122 & 15.1 \\
$(0.4 \mathrm{~g} / 100 \mathrm{ml})$ & 119 & 14.1 \\
UHMWP & 106 & 15.8 \\
$(0.6 \mathrm{~g} / 100 \mathrm{ml})$ & 115 & - \\
$\begin{array}{c}\text { Sholex } 6009 \\
\text { Sholex } 4551 \mathrm{H}\end{array}$ & 118 & 15.8 \\
Sholex $5551 \mathrm{H}$ & 120 & 18.1 \\
\hline
\end{tabular}

evaluated from Figures 5 and 7 and the interfacial thickness $t$ evaluated from Figures 15 and 16. Interestingly, although molecular weight plays an important role to form superstructures of polyethylene, it does not

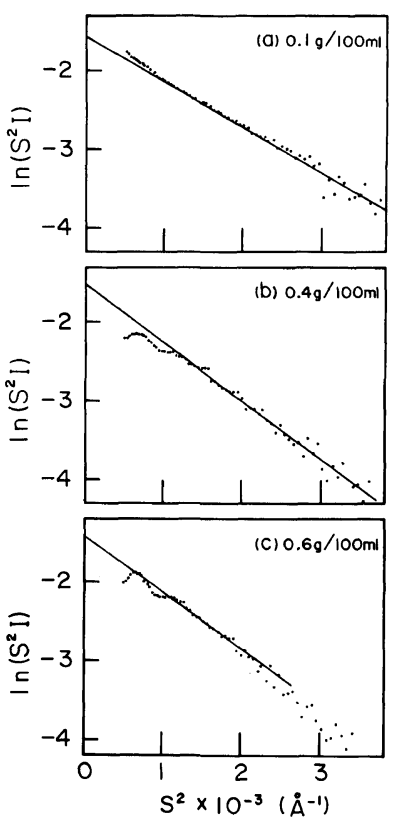

Figure 16. Full analysis of the interfacial thickness, $\ln \left(s^{2} I(s)\right) v s . s^{2}$ of dry gel films of UHMWP crystallized from solutions with concentrations of $0.1,0.4$, and $0.6 \mathrm{~g} / 100 \mathrm{ml}$.

give significant change in $L$ and $t$. Therefore, $L$ and $t$ are approximated as 120 and $15 \AA$, respectively, in order to propose a schematic diagram representing the morphology of dry gels as detailed models. Furthermore, crystallinities for all specimens are assumed to be $80 \%$. Figure 17 shows the diagram, in which three models on the left hand show the morphology of the dry LMWP gels and those on the right hand show that of the dry UHMWP gel film. As can be seen in the figures, the dry gel of LMWP composed of the two-dimensional spherulites stacked on the top of one another to form a periodic structure perpendicular to the plane of the dry gel. The periodic structure reflects the scattering maxima of SAXS intensity distribution in Figure 5. Within the spherulite, the crystal lamellae are rotated around a radial direction but the crystal lamellae are hardly connected to each other with entanglements which act as intermolecular crosslinks. On 

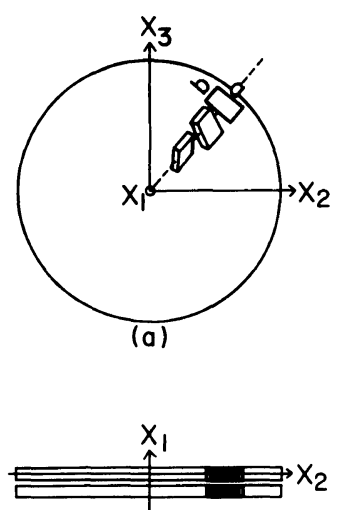

(b)

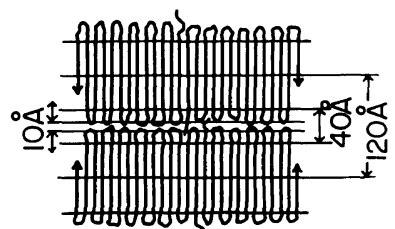

(c)

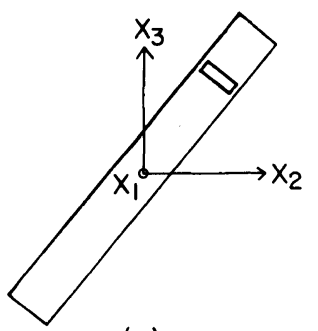

(a)

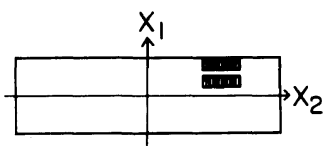

(b)

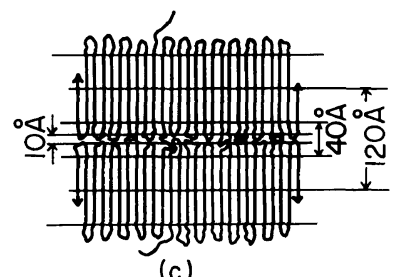

(c)

Figure 17. Schematic diagram of dry gels of LMWP on the left side and UHMWP on the right side.

the other hand, the dry gel films of UHMWP are composed of rodlike textures oriented parallel to the plane of the film. Within the rod, large lamellar crystals are highly oriented with their flat faces parallel to the rod surface, as discussed already (Figure 7). The crystal lamellae are connected to each other by tie molecules which form entanglements and the number of entanglements is dependent upon the concentration of solution to prepare gels. In the case of molecular weight used in this experiment, $0.4 \mathrm{~g} / 100 \mathrm{ml}$ was the best concentration to ensure a suitable level of entanglements that effectively transmit the drawing force for ultradrawing.

\section{CONCLUSIONS}

The morphological properties of polyethylene gels were investigated in relation to molecular weight dependence. Four kinds of LMWP and UHMWP were used as specimens. The gels of LMWP have no ability to form a film. They are composed of two-dimensional spherulites stacked on top of one another to form periodic structures perpendicular to the plane of the dry gel. Within the spherulite, the crystal lamellae are rotated around a radial direction. The crystallinities were beyond $80 \%$ for three specimens except $\mathrm{G} 201$ having a high degree of branchings. However, the crystallinities of the melt films, obtained from the melt of dry gels, decreased to $61-70 \%$. These values are much lower than those of dried gels. Thus, one conclusion can be drawn that dry gels of LMWP have a very few number of entanglements which act as interlamellar crosslinks because of high crystallinity, while the melt films have considerable entanglements because of lower crystallinity.

In contrast, a gel of UHMWP can form a film and it is composed of rodlike textures oriented parallel to the plane of the dry gel film. Within the rod, large crystal lamellae like single crystal mats are highly oriented with 
their flat faces parallel to the rod surface. The formability of films is due to a suitable number of entanglements and the entanglements are important to assure ultradrawing up to consistently high draw ratios.

\section{REFERENCES AND NOTE}

1. A. J. Pennings, J. M. M. A. van der Mark, and J. C. Booij, Kolloid Z.Z. Polym., 236, 99 (1973).

2. A. J. McHugh and J. M. Schulz, Kolloid Z.Z. Polym., 251, 193 (1973).

3. A. Zwijnenburg and A. J. Pennings, Colloid. Polym. Sci., 254, 868 (1976).

4. G. Capaccio and I. M. Ward, Polymer, 15, 233 (1974).

5. A. Zwijnenberg and A. J. Pennings, Colloid. Polym. Sci., 253, 452 (1975).

6. S. Kojima, C. R. Desper, and R. S. Porter, J. Polym. Sci., Polym. Phys. Ed., 16, 1721 (1978).

7. J. Clements, G. Capaccio, and I. M. Ward, J. Polym. Sci., Polym. Phys., Ed., 17, 693 (1979).

8. A. J. Owen and I. M. Ward,J. Macromol. Sci.-Phys., B19 (1), 35 (1981).

9. J. Smook, J. C. Torfs, P. F. van Hutlten, and A. J. Pennings, Polym. Bull., 2, 293 (1980).

10. P. J. Barham and A. Keller, J. Mater. Sci., 15, 2229 (1980).

11. P. Smith and P. J. Lemstra, J. Mater. Sci., 15, 505 (1980).

12. P. Smith, P. J. Lemstra, and H. C. Booij, J. Polym. Sci., Polym. Phys. Ed., 19, 877 (1981).

13. P. Smith, P. J. Lemstra, J. P. L. Pippers, and A. M. Kiel, Colloid. Polym. Sci., 258, 1070 (1981).

14. M. Matsuo, K. Inoue, and N. Abumiya, Sen-i Gakkaishi, 40, 275 (1984).

15. C. Sawatari and M. Matsuo, Colloid. Polym. Sci., 263, 783 (1985)

16. W. O. Statton, J. Appl. Phys., 38, 4149 (1967).

17. K. Ishikawa, K. Miyasaka, and M. Maeda, J. Polym.
Sci., $A-2$, 7, 2029 (1969).

18. K. Furuhata, T. Yokokawa, and K. Miyasaka, J. Polym. Sci., Polym. Phys. Ed., 22, 133 (1984).

19. T. Kanamoto, A. Tsuruta, K. Tanaka, M. Takeda, and R. S. Porter, Polym. J., 15, 327 (1983).

20. M. Matsuo, Nihon Reoroji Gakkaishi, 13, 4 (1985).

21. P. S. Francis, R. jr Cook, and J. H. Elliott, J. Polym. Sci., 31, 453 (1957).

22. M. Matsuo, C. Sawatari, M. Iida, and M. Yoneda, Polym. J., 17, 1197 (1985).

23. M. Matsuo and R. S. T. Manley, Macromolecules 15, 985 (1982).

24. M. Matsuo and R. S. T. Manley, Macromolecules 16, 1500 (1983).

25. R. S. Stein and M. B. Rhodes, J. Appl. Phys., 31, 1873 (1960).

26. M. B. Rhodes and R. S. Stein, J. Polym. Sci., A-2, 7, 1538 (1969).

27. F. Ozaki,T. Ogita, and M. Matsuo, Macromolecules, 14, 299 (1981)

28. M. Motegi, T. Oda, M. Moritani, and H. Kawai, Polym. J., 1, 209 (1970).

29. L. Mandelhern, M. Glotin, and R. A. Benson, Macromolecules, 14, 22 (1981).

30. G. Capaccio, A. G. Gibson, and I. M. Ward, "Ultrahigh Modulus Polymer," A. Ciferri and I. M. Ward, Ed., Applied Science Publishers, London, p 1.

31. S. B. Warner, J. Polym. Sci., Polym. Phys. Ed., 16, 2139 (1979).

32. M. Matsuo, M. Tsuji, and R. S. T. Manley, Macromolecules, 16, 1505 (1983).

33. M. Matsuo, C. Sawatari, M. Tsuji, and R. S. T. Manley, J. Chem. Soc., Faraday Trans. II, 79, 1593 (1983).

34. M. Matsuo and C. Kitayama, Polym. J., 17, 479 (1985).

35. T. Hashimoto, M. Shibayama, and H. Kawai Macromolecules, 13, 1237 (1980).

36. Instead of $s^{-2}$ in eq $1, s^{-4}$ has been employed for general system having orientational fluctation of lamellae. 